\title{
Screening and isolation of substitute-rennet producing thermophilic phycomycetes, by modified Warcup method and improved selective medium
}

\author{
Khademi F. ${ }^{*}$, Abachi S. ${ }^{2}$, Mortazavi A. ${ }^{3}$, Ehsani M.A. ${ }^{4}$, Tabatabaei M.R. ${ }^{5}$, \\ Malekzadeh F.A. ${ }^{6}$ \\ ${ }^{1,3}$ Department of Microbiology, Agriculture Research Center, Tabriz, Iran \\ ${ }^{2,6}$ Department of Food Science, Agriculture \& Natural Resources Research Center, Qom, Iran \\ ${ }^{4,5}$ Department of Biotechnology, QAUB Research Center, Tabriz, Iran \\ *Corresponding author; frank.khad@gmail.com
}

\begin{abstract}
Fungal milk-clotting enzymes are as valuable as bovine Chymosin in the cheese industry. Members of the Mucoraceae family, have important biotechnological potential as some species are enzyme producers at industrial scale. In this study, 31 isolates of thermophilic Phycomycetes of different taxa were selected from different sample sites and were studied for their aspartic protease producing capabilities. For primary isolation, modified Warcup method using improved Phycomycetes selective solid media along with high temperature selective for thermophilic Mucorals were applied. The purpose of this study was to collect the local biotechnologically important strains of thermophilic phycomycetes capable of producing rennin-like proteases. Based on a high relative enzyme activity (REA), the majority (83.7\%) of the 31 species of isolated thermophilic Phycomycetes were selected for next isolation steps. By trial production of acid proteases using shake flask fermentation, Milk clotting activity (MCA), and Protease activity (PA) of each fermentation broth of primary isolates were measured. Later, based on their high MCA/PA ratio, three isolates were chosen for macroscopic and microscopic examinations of each isolate determining their taxonomy identification and classification. The results showed that two of final isolates (HPA-O1 and ZDO-16) belong to Rhizomucor family (R. nainitalensis and R. pusillus) and the third thermophilic Zygomycetes (ZDP-03) is a Rhizopus (R. rhizopodiformis). Of the 3 isolates, Rhizomucor nainitalensis was chosen for further studies and could be introduced as a commercially important isolate in future.
\end{abstract}

Keywords: aspartic proteases, isolation, Phycomycetes, thermophilic fungi

\section{Introduction}

The enzymatic breakage of few specific amino acid bands in casein micelles is the primary phase of rennet coagulation [1]]. Chymosin, so-called Rennin (EC 3.4.23.4) extracted from calf rennet, has the highest proteolytic specificity on bovine milk by attacking and breaking few phe-met bands mostly in K-Casein $[\underline{2}, \underline{3}]$. Different acid or alkaline proteinases are able to coagulate milk, but most of them show little specificity for casein hydrolysis and are too proteolytic by hydrolyzing all the three casein fractions [4,5]. In almost all cheese varieties, the general proteolytic activity of the coagulant is of great importance to the product yield and the development of flavor and texture during ripening [6]. Increased worldwide demand for cheese coupled with reducing supply of calf rennet, has obliged scientists to search for rennet substitutes [ [7].

Animal and plant proteases has shown to be inappropriate sources of rennin-like enzymes because their output is limited or they may produce bitter tasting cheese []]. Consequently, attention has been turned to rennet substitutes from microbial sources due to their advantages, like easy culturing and short growth periods of microorganisms and their extracellular protease suitability for dairy industries [9]. The biosynthesis of enzymes by bacteria or fungi assures potential and unlimited supply of economically produced enzymes and also makes it possible to design new enzymatic systems that cannot be obtained from plant or animal sources [4]. At present, milk-clotting enzymes of microfungal origins are of major importance and thus, their rennets are used for more than one-third of dairy industry worldwide $[9, \underline{10}]$.

Amongst microfungi Zygomycetes have been shown to be in the first place, being second to calf rennet, since their mixture of proteases is the most favorable milk coagulant for cheese making [11]. The fungal Mucorales , as the largest order of Zygomycete fungi ,comprise an omnipresent group of thermophilic fungi known important to human allies $[11,12]$. Genus of Mucor is almost exclusively for synthesizing organic acids, alcohols and used for the commercial production of extracellular amylases, lipases, pectinases and proteases used in different industries.

Although in recent years other strains like Rhizopus [13], Penicillium and Aspergillus [14,15] have drawn attention as a producer of rennin-like enzyme but proteases synthesized by Mucor species [16-18] have 
been proven to be a better substitute for calf rennet. Today, Mucor rennet substitutes extracted from culture medium of M. miehei [19] and M. pusillus [20] are of commercial value. These milk curdling enzymes have generally been preferred as a substitute for true calf rennet because of their specificity in splitting similar peptide bond in kappa-casein, their easy extraction from fermentation broth, economical production, high ratios of milkclotting activity to proteolytic activity, similar calcium requirements, and good cheese quality [17].

Thermophilic fungi are a small assemblage in eukaryota and based on Cooney and Emerson [21] they grow at or above $50^{\circ} \mathrm{C}$ exceeding $62^{\circ} \mathrm{C}$ and fail to grow at or below $20^{\circ} \mathrm{C}$. They constitute a heterogeneous physiological group of 50 species in phycomycetes (the Zygomycetes and Ascomycetes), Deuteromycetes (Anamorphic Fungi), and Mycelia sterilia [22,23].

Thermophilic fungi such as Mucor, so-called dung mold, is a coprophilous fungi which typically occurs as saprophytes in acid thermal soil habitats and in decomposition sites of plant material. They can be isolated from a variety of standard mycological organic matters e.g. herbivorous dung, manure, compost, birds' nesting material, wood chip piles, snuff, deserts, beach sands ,piles of hays, other accumulations of organic materials and even desert soils composts [24]. Techniques used for isolation of fungi from soil include serial dilution agar plate, Warcup as the extension of solid soil plate, syringe inoculation, immersion tube method, screened immersion plates, plate profile, hyphal isolation, soil washing, partial presterilization, soil sieving, floatation, baiting, and a few others. Most common technique in use is the solid media, which speeds up the screening of large populations of fungi, allowing the detection of specific enzymes and helping in the taxonomical differentiation of many microorganisms.

The aim of this study is to isolate and to identify thermophilic Phycomycetes from soil, compost and herbivores dung, with special focus on the selection of Mucorals as the producers of milk-clotting enzymes and to determine the ratio values of each isolates' milk-coagulating activity (MCA) to its proteolytic activity (PA). Warcup method with certain modifications was applied to utilize a faster and more selective process. This may lead to identification of new strains with extracellular rennin-like acid proteases and high relative enzyme activity (REA) applicable in dairy industry.

\section{Materials and Methods}

Merck, Oxoid and BioM were the brands of reagents /chemicals used in this study.

\subsection{Sample collection (soil cores)}

For the isolation of thermophilic Phycomycetes, the soil samples were collected from three sites of Tehran great Eram Zoo (35.717855 N, 51.293822 E)- dung/trash pile, Hara protected Area (26.885325 N, 55.769176 E) - Soil with a tropical weather and Miankaleh Wildlife Sanctuary and Wetland (36.858469 N, 53.413038 E) - Soil with a Mediterranean climate.

The samples from Zoo were a mixture of droppings of various zoo animals mostly herbivores, poultris' manure, and a smaller portion of plant debris. Samples were collected from deeper part of the pile. The soil samples from each habitat were collected randomly from the superficial layer of soil not exceeding 5-6 cm depth using pre-sterilized corer and were transferred into sterilized polythene bags. Samples were taken to the laboratory and were thoroughly mixed to form a composite sample which was stored at $15^{\circ} \mathrm{C}$ until next day processing.

\subsection{Culture media and isolation and purification method}

Thermophilic fungi from different sources/substrates were isolated by standard isolation procedures according to Cooney and Emerson [21] using standard media of YpSs agar: Yeast extract, 4 g; K2HPO4, $1 \mathrm{~g}$; MgSO4.7H2O, 0.5 g; Soluble starch, 15 g; Agar, 20 g; Distilled water, $750 \mathrm{ml}$; Tap water, $250 \mathrm{ml}$.

Partially selective medium was prepared by adding $150 \mu \mathrm{g} / \mathrm{ml}$ streptomycin sulphate, and Rose Bengal $(50 \mu \mathrm{g} / \mathrm{L})$ to YpSs agar medium for primary isolations. Additionally, BENOMYL (1-(butylcarbamoyl)-2benzimidazole carbamic acid methyl ester) was added to make the final concentration of $10 \mu \mathrm{g} / \mathrm{ml}$. Benomyl was added to the medium prior to autoclaving, then the medium was cooled . Streptomycin and Rose Bengal were added before the medium was poured into petri dishes.

\subsection{Direct soil plating by Warcup method}

To each sterile Petri plates, $0.1 \mathrm{~g}$ of air-dried sample was added using a sterilized cooled loop or transfer needle. Then $15-20 \mathrm{ml}$ of melted and cooled $\left(45^{\circ} \mathrm{C}\right) \mathrm{YpSs}$ medium, was supplemented with streptopenicillin and Rose Bengal. Benomyl was added, to each soil inoculated petri plate. Sample particles were dispensed throughout the medium by gentle rotation of the petri dishes and were allowed to solidify. Five plates from each soil sample were incubated in an inverted position in $55^{\circ} \mathrm{C}$ for 3 days [25]. To avoid desiccation of the agar medium because of elevated temperature, petri plates were incubated in a damp chambers holding adequate moisture in all cultures at the higher incubation temperature [26-28]. The plates were observed every 12 hours for the appearance of the fungal colonies during the 3 days incubation. 
Various isolated fungi were purified up to specific level for upcoming applications and for identification by repeated point inoculation method on the plates containing PDA (potato dextrose agar) medium. During repeated point inoculation, each formed colony were transferred to new PDA plates and incubated at the identical conditions. Each morphologically unique fungal colony was continuously transferred into new agar plates until pure colonies (isolates) were obtained. A pure culture was rated by its homogenous morphological appearance in size, shape, spore color, and mycelium color. Furthermore, the reverse of the plates were checked to ensure they were colorless, indicating that no competition between two or more different colonies has occurred. In addition, the purity of the isolated fungus was confirmed by microscopic examination of the culture at 400X magnification using light microscopy. After ensuring purity, the cultures were subcultured on PDA slants and allowed to grow for a period of 3-5 days and subsequently stored at $4{ }^{\circ} \mathrm{C}$ as stock cultures [29].

\subsection{Determination of proteolytic activities}

\subsubsection{Primary screening of the isolates on solid media for rennet production}

Inoculated Agar Reese's medium (containing 0.5\% casein as protein substrate ) plates were incubated at $35^{\circ} \mathrm{C}$ to allow the growth of the isolated fungi for 2 days . They were then examined for the formation of clearance zone, by flooding the plates with a solution of 5\% Trichloroacetic acid (TCA). The plates were kept for 30 minutes in this solution to allow the precipitation of residual proteins in the medium. In the next step, the diameters of both the fungal colony and the halo of hydrolysis were measured in each case. On the basis of this ratio, relative enzyme activity (REA) was calculated and strains with the higher ratio were selected for the next steps $[\underline{30}, \underline{31}]$.

\subsubsection{Fermentation and production of acid proteases in the liquid media}

Isolates with a clear zone of deposit were selected and grown in broth medium. Production trials of acid protease were performed in a $300 \mathrm{ml}$ erlen containing $30 \mathrm{ml}$ liquid culture medium composed of soybean meal $(40 \mathrm{~g} / \mathrm{l})$, corn starch $(10 \mathrm{~g} / \mathrm{l}), \mathrm{NH} 4 \mathrm{Cl}(8 \mathrm{~g} / \mathrm{l}), \mathrm{CaCl} 2(5 \mathrm{~g} / \mathrm{l}) \mathrm{Na} 2 \mathrm{HPO} 4(2 \mathrm{~g} / \mathrm{l})$. For seeding, each erlen was inoculated with a spore suspension $(3 \% \mathrm{~V} / \mathrm{V})$. The fermentation conditions were a growth temperature of $35^{\circ} \mathrm{C}$ on a rotary shaker with a shaking speed of $150 \mathrm{rpm}$ and an incubation time of 48 hours. After incubation period, samples were withdrawn and centrifuged at $5000 \mathrm{rpm}$ for 15 minute. The supernatant or crude extract was stored at $4^{\circ} \mathrm{C}$ for the assay of milk-clotting activity (MCA) and proteolytic activity (PA).

\subsubsection{Secondary screening: determination of milk-clotting to proteolytic activity (MCA/PA ratio) of culture supernatant}

The determination of MCA and PA (Caseinolytic activity) was made directly on supernatant (rough culture extract) obtained after centrifugation.

Milk Clotting activity of the rennet was evaluated using the method of Arima [32] and represented in Soxhlet unit (SU). One Soxhlet unit is defined as the amount of enzyme that clots $1 \mathrm{ml}$ of substrate $(0.1 \mathrm{~g}$ skim milk powder and $1.47 \mathrm{mg} \mathrm{CaCl} 2$ ) in $40 \mathrm{~min}$ at $35^{\circ} \mathrm{C}$. The time taken for the milk to curdle at $35^{\circ} \mathrm{C}$ was recorded and enzyme activity calculated from the following formula:

$$
U=\frac{M(m \cdot l)}{E(m \cdot l)} \times \frac{35^{\circ}}{t^{(c)}} \times \frac{2400}{T(s e c)}
$$

Where $\mathrm{U}=$ curdling potential of the enzyme measures in Soxhlets, $\mathrm{M}=$ milk, $\mathrm{E}$ : volume of enzyme, $\mathrm{t}=$ defines the temperature of substrate enzyme reaction, $\mathrm{T}=$ time taken for the curdle to form

The proteolytic activity was determined, method of Kunitz [33] , using the substrate of Casein and was expressed in units per $\mathrm{ml}(\mathrm{U} / \mathrm{ml})$. Briefly, $1 \mathrm{ml}$ of enzyme solution was added to $5 \mathrm{ml}$ of substrate solution containing $1.2 \%$ of casein solution in 0.05 Mole phosphate buffer $(\mathrm{pH} 6.0)$. The mixture was incubated at $35^{\circ} \mathrm{C}$ for $10 \mathrm{~min}$ then $5 \mathrm{ml}$ of 0.44 Mole Tri-Chloroacetic Acid (TCA) was added to inhibit the reaction. After filtration, $2 \mathrm{ml}$ of the filtrate was added to $5 \mathrm{ml}$ of $\mathrm{NaOH}$ solution $0.28 \mathrm{~N}$. Later $1.5 \mathrm{ml}$ of Folin-Ciocalteu phenol solution $50 \%$ was added to the mixture. After incubation of the mixture in $35^{\circ} \mathrm{C}$ for $15 \mathrm{~min}$, optical density (OD) was measured at $660 \mathrm{~nm}$ by spectorophotometer, which directly expresses the enzyme activity.

Strains that showed the highest ratio of milk-clotting activity to proteolytic activity $\left(\mathrm{SU}_{/} \mathrm{OD}_{660}\right)$ were selected for further studies.

\subsubsection{Identification and classification of the fungi}

Microscopy examinations were performed on three selected fungal colonies grown on Potato Dextrose agar (PDA). The morphologic and culture characteristics of each colony were analyzed. These characteristics 
such as Colony growth (length and width), presence, or absence of aerial mycelium, colony color, presence of wrinkles and furrows, pigment production etc. were compared with the standard descriptions [34-36]. The final part of identification to the species level was done by microscopic analysis using taxonomic guides and standard procedures. The slides of each fungus were mounted using Lacto phenol cotton blue and were observed under microscope. Cultures as well as stock cultures were maintained and transferred to fresh PDA slants at regular intervals of 3 months.

\subsection{Culture media, isolation, purification of thermophilic fungi}

Thermophilic Zygomycetes like many other microfungi have very simple nutritional requirements and grow in the presence of a heat source either sunlight or a microbial fermentation. The sites selected for this study, exhibited heterogeneity with regard to temperature, $\mathrm{pH}$, moisture content, altitude, and vegetation cover. We selected these sites because their temperate, eurythermal conditions or dense vegetation suggested a high fungal diversity and therefore they would be interesting to characterize.

The dilution plates and soil plate methods are two most widely used methods for the fungal isolation from soil. Warcup soil plate, an extension of direct soil plate method, was developed by Warcup [37] and is more appropriate than dilution plate method because it provides accurate qualitative information, is convenient to use, much faster when handling a great number of isolates and requires less glassware.

To make the media selective for fungi, Rose Bengal and streptomycin were added which inhibits the growth of almost any bacteria. In addition, we added up BENOMYL (Benlate) to make the media selective for Phycomycetes and therefore exclude a great number of unwanted fungi. Benomyl is, since 1970, registered as a systemic fungicide in a great number of countries and similar to other benzimidazole fungicides. While Benomyl is active against a broad spectrum of fungi, among which are Ascomycetes, Basidiomycetes and some Deuteromycetes, it is found completely inactive against the Phycomycetes fungi [38,39]. The Phycomycetaceae is a family of fungi in the order of Mucorales. The two Phycomycetes, Mucor and Rhizopus are not significantly affected by a single application of Benomyl, although the numbers isolated from experimental plots were generally higher than those isolated from control plots [40].

The third selective parameter applied in this isolation was raising the incubation temperature to $55^{\circ} \mathrm{C}$ which greatly would limit the number of Phycomycetes to only thermophilic strains. Application of these parameters would possibly lead us to selecting a fungus that belongs to the Mucoraceae family as the favorable producers of substitute rennet. Total of 31 fungal forms were obtained from the positive samples, including 21 fungal species from Zoo dung pile, 7 from Hara Protected Area's soils and 3 from Miankaleh Wildlife Sanctuary and Wetland's soil. Samples varied significantly with respect to altitude, $\mathrm{pH}$ and organic carbon contents (on sunny days soil temperature increases to above $20^{\circ} \mathrm{C}$ consequently increasing the $\mathrm{pH}$ ). Soil's $\mathrm{pH}$ of Hara Protected Area is categorized as slightly acidic whereas Miankaleh Wildlife Sanctuary and Wetland is slightly alkaline ( $\mathrm{pH}$ 7.3). However, apparent relationship between soil $\mathrm{pH}$ and the number of CFUs wasn't determined. The soils had snow cover at least once in a year and moisture content was much higher in the winter than in the summer months. A negative correlation between the number of fungal species and the altitude is established, the number of fungal species isolated were more at lower altitudes.

In this part of study, a total of 38 samples were found positive for the occurrence of thermophilic Phycomycetes.

\subsection{Results of screening strains producing protease}

Second phase of the selection was done according to the screening for isolates with the ability to hydrolyze Casein as the main protein of milk [30]. Solid medium providing rapid assays was used for the direct enumeration and isolation of protease-producing fungi (using point inoculation of fungal spores on skimmed milk agar). The main criteria for the selection of fungal strains were the hydrolysis of milk casein (clear zones around the colony, a halo size larger than $3 \mathrm{~mm}$ was considered significant) and the mycelium colony diameter( must be greater than $9 \mathrm{~mm}$ ). All isolates in step one were found to have protease activity in their neighboring agar medium when tested by using casein as a protein substrate in the media. The ratio value is an interesting parameter for evaluating the ability of the selected wild strains to produce proteases on solid agar media. A total of 26 strains $(83.7 \%$ of total isolates, 17 of Zoo dung samples, 7 of Hara wildlife area's soil and 2 of Miankaleh Wildlife Sanctuary and Wetland's soil) were selected because of their interesting proteolytic activities.

\subsection{Test production of acid protease by wild strains}

Protease activity of enzymes can be measured through several methods, all methods use grinded skimmed milk, hemoglobin, or Casein as substrate. Chosen method was Kunitz proteolytic assay as it uses Casein as assay's substrate (Casein is considered the main protein of bovine milk and the produced cheese). The values of the obtained proteolytic activities were between 0.11 and $0.9 \mathrm{U} / \mathrm{ml}$. They vary according to the strains 
Screening and isolation of substitute-rennet producing thermophilic phycomycetes, by modified

tested, and a maximum production was shown by the strain ZDP-07. However, the strains ZDP-12 and ZDP-05 gave relatively high proteolytic activity value for wild strains $(0.58$ and $0.52 \mathrm{U} / \mathrm{ml})$.

In addition to proteolytic activity, the culture supernatants obtained from the cultures were measured for MCA. According to the results, HPA-05 showed the least MCA, $130 \mathrm{SU} / \mathrm{mL}$, and ZDP-02 with $1140 \mathrm{SU} / \mathrm{ml}$ had the highest MCA. Isolate MWW-03 with $970 \mathrm{SU} / \mathrm{ml}$ and Isolate ZDP-07 with $920 \mathrm{SU} / \mathrm{ml}$ were the second and third higher producers, respectively. The protease activity and milk clotting activity of culture filtrates of all the 26 fungal isolates are given in Table 1 .

Table 1 "Milk-clotting activity (MCA) and proteolytic activities (PA) produced by various strains of thermophilic phycomycetes isolated from multiple sample cores"

\begin{tabular}{|c|c|c|}
\hline Isolate Number & MCA (SU/ml) & PA $\left.\mathbf{( O D}_{\mathbf{6 6 0}}\right)$ \\
\hline ZDP-01 & 490 & 0.46 \\
\hline ZDP-02 & 1140 & 0.35 \\
\hline ZDP-03 & 310 & 0.11 \\
\hline ZDP-04 & 890 & 0.18 \\
\hline ZDP-05 & 320 & 0.52 \\
\hline ZDP-07 & 920 & 0.9 \\
\hline ZDP-08 & 760 & 0.37 \\
\hline ZDP-10 & 180 & 0.29 \\
\hline ZDP-11 & 630 & 0.43 \\
\hline ZDP-12 & 410 & 0.58 \\
\hline ZDP-14 & 860 & 0.31 \\
\hline ZDP-15 & 380 & 0.28 \\
\hline ZDP-16 & 710 & 0.16 \\
\hline ZDP-18 & 420 & 0.35 \\
\hline ZDP-20 & 250 & 0.17 \\
\hline ZDP-21 & 330 & 0.46 \\
\hline HPA-01 & 620 & 0.12 \\
\hline HPA-02 & 340 & 0.31 \\
\hline HPA-03 & 150 & 0.24 \\
\hline HPA-04 & 210 & 0.39 \\
\hline HPA-05 & 130 & 0.39 \\
\hline HPA-06 & 670 & 20 \\
\hline HPA-07 & 430 & 18 \\
\hline MWW-02 & 380 & 0.27 \\
\hline MWW-03 & 970 & \\
\hline & & \\
\hline & & \\
\hline & 30.44 \\
\hline
\end{tabular}

$\mathrm{MCA} / \mathrm{PA}$ ratio is one the most important criteria of a rennin-like enzyme to be considered suitable for cheese industry. A higher ratio can be translated as a higher product yield and a better quality of produced cheese. According to the result of this section of study (shown in figure 1) three strains, HPA-01 (51.67 SU/OD $\left.{ }_{660}\right)$, ZDP-04 (49.44 SU/OD 660$)$, and ZDP-16 (44.38 SU/OD 660$)$, with the considerably higher ratio were selected as the candidates for further studies including taxonomic classification.

\subsection{Fungal Identification and Taxonomy}

Today for most identification algorithms of thermophilic Zygomycetes the microscopic and macroscopic morphologies are qualified characteristics to classify each isolate. Therefore, other methods within phenotypic classification, analytic classification and genotypic classification such as guanine and cytosine ratio, DNA hybridization and ITS extension of nucleic acid sequence analysis would not seem necessary in this study.

To classify the isolates, colonies with different morphological forms were separated and sub-cultured on potato dextrose agar (PDA) and allowed to grow and sporulate to obtain pure isolates. During colony purity 
approval, all isolates selected from primary isolation were tentatively identified. Based on their macroscopic characteristics such as; colony color, production of pigment in medium, presence of aerial mycelium, width of colony, presence of wrinkles and presence of furrows, etc. The characteristics were compared with the standard descriptions by the reference of mycological literatures. In next step, three final isolates were classified down to the genus level by microscopic analysis using taxonomic guides and standard procedures. The microscopic observation of selected strains was on the colonies with sporulation, of a diameter greater than $9 \mathrm{~mm}$. The microscopic observation of mycelium, revealed the presence of mitospores endogenous formed in sporangia; zygospores formed by hyphal conjugation. These characters guided us to affiliation to the Class of Zygomycetes.

Further taxonomy studies revealed the Mucoral characteristics of all 3 isolates. Sporangiophore arising from trophocyst, thallus mycelial and sporangia multispored which consequently placed these isolates in the order of Mucorales. Moreover, characteristics such as sporangia columellate, absence of specialized sporangiola , zygospores smooth to warty, borne on opposed, tongs-like or apposed, naked or appandaged suspensors; polyphyletic were the proof that they belong to the Family of Mucoraceae.

Further taxonomic study revealed that 1 isolate classified as Rhizopus rhizopodiformis because of the following indications; sporangiospores striate, sporangiophores unbranched, sporangia globose and originating from distinct rhizoids. In addition, the other 2 isolates were placed in the genus of Rhizomucor by showing the following criteria; sporangiophores branched, sporangiospores not striate or angular, sporangia globose, apophysis absent and not originating from distinct rhizoids. One isolate was classified as Rhizomисor nainitalensis as dumb-bell shaped sporangiospores were the unique sign of this genus.

The last isolated strain classified as Rhizomucor pusillus (Mucor pusillus) since macroscopic and microscopic characteristics fall in the following descriptions: no zygospores and a heterothallic fungi. Colony is initially white later turning grayish with whitish margin, becoming grayish black at maturity, mycelial turf 2-3 $\mathrm{mm}$ high. Sporangiophores sympodially branched, $10-15 \mu$ in diameter, colourless to yellow brown. Sporangia 50-80 $\mu$ in diameter, spinulose, rupturing at maturity, columellae subglobose to slightly elongate, $15-35 \mu$ in diameter and up to $60 \mu$ long, sporangiospores colourless, globose to sub-globose, 3-5 $\mu$ in diameter and Chlamydospores was absent.

In this study, maximum MCA/PA ratio (51.67 SU/OD660) was recorded for culture supernatant of isolate HPA-01 classified as Rhizomucor nainitalensis, which makes this isolates the candidate for further studies answering the question if commercialization of this isolate can be considered in future. Two other isolates of Rhizopus rhizopodiformis (ZDP-03) and Rhizomucor pusillus (ZDO-16) produced substitute rennets with lower ratios of 49.44 SU/OD660 and 44.48 SU/OD660 respectively. Although they show considerably less MCA/PA ratio but still they may provide a good quality product suitable for cheese industries and so they were freeze-dried as spare candidates for future investigation [41]. Other researchers have also reported Acid protease production by their test strains of these species. Overall, the results obtained during this investigation and those reported by others indicates that Rhizomисor is one of the important genera for the production of substitute rennet.

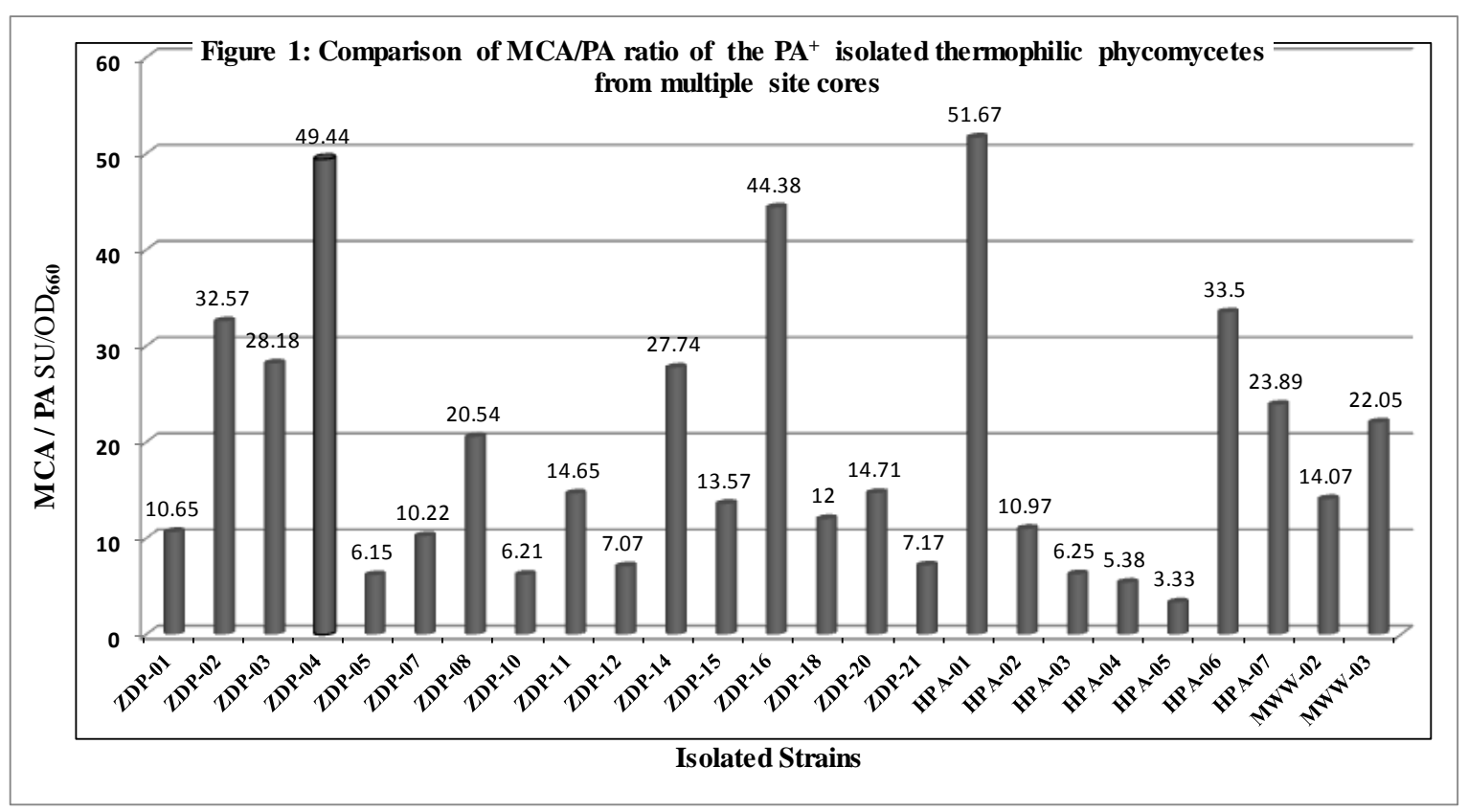

Acknowledgment 
We greatly thank the Agricultural Research Center of the province of East Azerbaijan for their financial support and collaboration to perform this research project.

\section{References}

[1] Ekstrand B, Larsson-Raznikiewicz M, Perlmann C. (1980): Casein micelle size and composition related to the enzymatic coagulation process. Biochim Biophys Acta, 630(3), 361-366.

[2] Visser S, Van Rooijen PJ, Schattenkerk C, Kerling KE. (1976): Peptide substrates for chymosin (rennin). Kinetic studies with peptides of different chain length including parts of the sequence 101-112 of bovine k-casein. Biochim Biophys Acta, 438(1), 265-272.

[3] Hsieh JF, Pan PH. (2012): Proteomic profiling of the coagulation of milk proteins induced by chymosin. J Agric Food Chem, 60(8), 2039-2045

[4] Bailey MJ, Siika-aho M. (1988): Production of microbial rennin. Biotechnol Lett, 10(3), 161-166.

[5] Kumar A, Grover S, Sharma J, Batish VK. (2010): Chymosin and other milk coagulants: sources and biotechnological interventions. Crit Rev Biotechnol, 30(4), 243-258

[6] O'Mahony JA, Lucey JA, McSweeney PL. (2005): Chymosin-mediated proteolysis, calcium solubilization, and texture development during the ripening of cheddar cheese. J Dairy Sci, 88(9), 3101-3114.

[7] Winwood J. (1989): Rennet and rennet substitutes. International journal of dairy technology, 42(1), 1-2.

[8] De Apodaca O. (1994): Study of the milk-clotting and proteolytic activity of calf rennet, fermentation-produced chymosin, vegetable and microbial coagulants. Milchwissenschaft, 49(1), 13-16

[9] Neelakantan S, Mohanty A, Kaushik JK. (1999): Production and use of microbial enzymes for dairy processing. Curr Sci, 77(1), 143-148.

[10] JACOB M, JAROS D, ROHM H. (2011): Recent advances in milk clotting enzymes. International journal of dairy technology, 64(1), 14-33.

[11] Maheshwari R, Bharadwaj G, Bhat MK. (2000): Thermophilic fungi: their physiology and enzymes. Microbiology and molecular biology reviews, 64(3), 461-488.

[12] Ong PS, Gaucher GM. (1973): Protease production by thermophilic fungi. Can J Microbiol, 19(1), 129-133.

[13] Chen CC, Cho YC, Lai CC, Hsu WH. (2009): Purification and characterization of a new Rhizopuspepsin from Rhizopus oryzae NBRC 4749. J Agric Food Chem, 57(15), 6742-6747.

[14] Chrzanowska J, Kolaczkowska M, Dryjanski M, Stachowiak D, Polanowski A. (1995): Aspartic proteinase from Penicillium camemberti: purification, properties, and substrate specificity. Enzyme Microb Technol, 17(8), 719-724.

[15] Yin LJ, Hsu TH, Jiang ST. (2013): Characterization of Acidic Protease from Aspergillus niger BCRC 32720. J Agric Food Chem.

[16] Merheb-Dini C, Garcia GAC, Penna ALB, Gomes E, da Silva R. (2012): Use of a new milk-clotting protease from Thermomucor indicae-seudaticae N31 as coagulant and changes during ripening of Prato cheese. Food Chem, 130(4), 859-865.

[17] Yegin S, Fernandez-Lahore M, Jose Gama Salgado A, Guvenc U, Goksungur Y, Tari C. (2011): Aspartic proteinases from Mucor spp. in cheese manufacturing. Appl Microbiol Biotechnol, 89(4), 949-960.

[18] Alves MH, de Campos-Takaki GM, Okada K, Ferreira-Pessoa IH, Milanez AI. (2005): Detection of extracellular protease in Mucor species. Rev Iberoam Micol, 22(2), 114-117.

[19] Mariani DD, Lorda GS, Balatti AP. (2003): [Rennet production by Rhizomucor miehei NRRL 3169]. Rev Argent Microbiol, 35(3), 128-132.

[20] JIANG Y, WANG J, LI Y, LI D, YANG Z. (2010): Cloning and expression of a rennet gene from mucor pusillus [J]. China Dairy Industry, 2, 003.

[21] Cooney DG, Emerson R. (1964): Thermophilic fungi. An account of their biology, activities, and classification. Thermophilic fungi. An account of their biology, activities, and classification.

[22] Salar RK, Aneja K. (2007): Thermophilic fungi: taxonomy and biogeography. Journal of Agricultural Technology, 3(1), 77-107.

[23] Mouchacca J. (1999): Thermophilic fungi: present taxonomic concepts. Thermophilic Moulds in Biotechnology, 43-83.

[24] Christenberry GA. (1940): A taxonomic study of the Mucorales in the Southeastern United States. Journal of the Elisha Mitchell Scientific Society, 56(2), 333-366.

[25] Houbraken J, Samson RA. (2006): Standardization of methods for detecting heat resistant fungi. Adv Exp Med Biol, 571, 107111.

[26] Maheshwari R, Bharadwaj G, Bhat MK. (2000): Thermophilic fungi: their physiology and enzymes. Microbiol Mol Biol Rev, 64(3), 461-488

[27] Tansey MR, Jack MA. (1976): Thermophilic fungi in sun-heated soils. Mycologia, 1061-1075.

[28] Tansey MR. (1971): Isolation of thermophilic fungi from self-heated, industrial wood chip piles. Mycologia, 537-547.

[29] Tansey M. (1984): Efficient isolation of thermophilic and thermotolerant mucoralean fungi. Mycopathologia, 85(1), 31-42.

[30] ARIMA K. (1967): Milk clotting enzyme from microorganisms, part I. Screening test and the identification of the potent fungus. Agric. Biol. Chem., 31, 540-545.

[31] Abachi S, Khademi F, Fatemi H, Malekzadeh F. (2013): Study of Antimicrobial activity of selected Iranian plant extracts on vancomycin resistant Staphylococcus epidermidis. IOSR Journal of Dental and Medical Sciences, 4(1), 59-63.

[32] Arima K. (1972): Mucor rennin. In'Conversion and manufacture of foodstuffs by microorganisms'[see FSTA (1976) 8 8G509].

[33] Kunitz M. (1947): Crystalline soybean trypsin inhibitor II. General properties. J Gen Physiol, 30(4), 291-310.

[34] MOUCHACCA J. (1997): Thermophilic fungi: biodiversity and taxonomic status. Cryptogamie. Mycologie, 18(1), 19-69.

[35] Ritter R. (1955): Physiological studies on Zygomycetes. Arch Mikrobiol, 22 (3), 248-284. 
[36] Shkurenko VO. (1967): Occurrence of thermophilic fungi of the order Mucorales in soil. Mikrobiol Zh, 29(1), 10-12.

[37] Warcup J. (1950): The soil-plate method for isolation of fungi from soil.

[38] Foster MG, McQueen DJ. (1977): Multiple applications of benomyl and effects on non-target soil fungi. Bull Environ Contam Toxicol, 17(4), 468-476.

[39] Bollen G. (1972): A comparison of the in vitro antifungal spectra of thiophanates and benomyl. European Journal of Plant Pathology, 78(2), 55-64.

[40] Peterson CA, Edgington L. (1969): Quantitative estimation of the fungicide benomyl using a bioautograph technique. J Agric Food Chem, 17(4), 898-899.

[41] Khademi F, Abachi S, Mortazavi A, Ehsani M.A., Tabatabaei M.R., Malekzadeh F.A. (2013): Optimization of physical and chemical parameters for the production of microfungal rennet by local isolate of Rhizomucor nainitalensis under Solid Substrate Fermentation system. IOSR Journal of Pharmacy and Biological Sciences, 5(3). 